Estudios de la Paz y el Conflicto

Revista Latinoamericana

IUDPAS-UNAH

Volumen 1, Número 1, pp. 97-115

ISSN-e: 2707-8922 / ISSN: 2707-8914

DOI: $10.5377 /$ rlpc.v1i1.9518

Enero-junio 2020

\title{
MIGRACIONES E IDENTIDAD. UNA APROXIMACIÓN DESDE LA TEORÍA DE LA IDENTIDAD COLECTIVA Y DESDE LA TEORÍA DEL SUJETO
}

\author{
MIGRATIONS AND IDENTITY. AN APPROACH FROM THE THEORY OF \\ COLLECTIVE IDENTITY AND FROM THE THEORY OF THE SUBJECT
}

\begin{abstract}
Antonio Álvarez-Benavides
City University of New York (CUNY)

Grupo de Estudios Socioculturales Contemporáneos (GRESCO-UCM)

Centre d'Analyse et d'Intervention Sociologique (CADIS-Internacional)

alvarezbenavides@gmail.com
\end{abstract}

Cómo citar / citation

Álvarez-Benavides, A. (2019). "Migraciones e identidad. Una aproximación desde la teoría de la identidad colectiva y desde la teoría del sujeto", Estudios de la Paz y el Conflicto, Revista Latinoamericana, Volumen 1, Número 1, 97-115. DOI: 10.5377/rlpc.v1i1.9518

\section{Resumen}

La globalización ha producido dos grandes fenómenos relacionados con la identidad. Por un lado, procesos de homogeneización social por la extensión de un modelo económico y cultural particular, por otro, la plurificación de las formas de ser por la multiplicación de la información. Este doble proceso, que es complementario, tiene un impacto singular en y debido a las migraciones transnacionales. Si en el pasado inmigrar suponía incorporarse a una nueva sociedad y apartarse de distintas maneras y con distintos niveles a las realidades culturales de esa sociedad, en el contexto global este proceso es mucho más complejo. En este texto, se intentará responder a estos procesos de adaptación, (re)construcción y (re)formulación de la identidad (cultural, religiosa y étnica) de los migrantes cuando se instalan en una nueva sociedad a través de dos grandes paradigmas teóricos: la teoría de la reproducción y la transmisión de la identidad colectiva (basado en un modelo fenomenológico-genético) de Alfonso Pérez-Agote; y la teoría del sujeto de Alain Touraine y de los procesos de subjetivación de Michel Wieviorka.

\section{Palabras clave}

Migraciones; identidad colectiva; sujeto; subjetivación; (re)producción; Alfonso PérezAgote; Alain Touraine; Michel Wieviorka. 


\begin{abstract}
Globalization has produced two important phenomena related to identity. On the one hand, processes of social homogenization by the extension of a particular economic and cultural model, on the other the plurification of forms of being by the multiplication of information. This double process, which is complementary, has a unique impact on and due to transnational migrations. If in the past immigrate meant integrating into a new society and into a new culture in different manners and with different levels, in the global context this process is much more complex. In this text, we will try to analyse the processes of adaptation, (re) construction and (re) formulation of migrants identity (cultural, religious and ethnic) when they settle in a new society, through two great theoretical paradigms: the theory of the reproduction and transmission of collective identity (based on a phenomenological-genetic model) by Alfonso Pérez-Agote; and the theory of Subject by Alain Touraine and the subjectivization processes by Michel Wieviorka.
\end{abstract}

\title{
Keywords
}

Migrations; collective identity; subject; subjectivization; Alfonso Pérez-Agote; Alain Touraine; Michel Wieviorka.

\section{INTRODUCCIÓN}

Quizá lo primero que sorprende y aprenden los estudiantes de sociología es que la realidad es una construcción social [Berger y Luckmann, 1969 (1999)]. Cada sociedad, cada grupo humano, ha ido creando a lo largo de la historia - también invención humana- toda una serie de categorías, de códigos, de significados, que nos han permitido organizarnos y, sobre todo, entendernos. A los sociólogos nos importa poco lo que nos diga la física o las matemáticas sobre la realidad, bueno, nos importa mucho, sobre todo a los que se dedican a la sociología de la ciencia, pero sabemos que la realidad no deja de ser un constructo, con unas formas que surgen del consenso y del disenso, fruto de la interacción social, y que se articula gracias al lenguaje. El género, la raza, la clase social, la ciencia, la religión son constructos, que cambian, evolucionan, que toman distintas características, pero que, en definitiva, son, porque nosotros somos, porque los hacemos ser. De eso trata la sociología, de saber cómo construimos y qué formas le vamos dando a la realidad.

Dentro de las distintas categorías sociales que conforman la realidad, la identidad se presenta como un reto especialmente interesante para las ciencias sociales y, principalmente, para la sociología. Aparentemente no hay nada que tenga que ver más con el individuo que su identidad, y los sociólogos nos interesamos por los hechos y por los procesos sociales, pero la identidad, como cualquier otra categoría social, tiene tanto de colectivo como de individual. En este juego contingente de capas y construcciones, de lo individual y de lo colectivo, la identidad tiene una esencia especialmente poliédrica, pues de hecho da cobijo en su ser a todo el resto de las categorías sociales: género, clase, etnia, edad... Por consiguiente, el estudio de la identidad es susceptible de ser realizado desde cualquier rama de la sociología al igual que desde cualquier paradigma teórico.

Este texto pretende reflexionar sobre la contingencia de los procesos identitarios relacionados con los fenómenos migratorios. Su origen estuvo en mi doctorado, en la 
necesidad teórica y práctica de coordinar dos grandes teorías, dos formas de abordar la identidad como categoría sociológica desde dos ópticas que podrían entenderse como contrapuestas, pues una hace referencia a lo colectivo, la teoría de la identidad colectiva, - su formulación, reformulación y transmisión- , desarrollada, principalmente, por Alfonso PérezAgote, y la otra, pone su foco de atención en el actor social, la teoría del sujeto, desarrollada por Alain Touraine. El peso de estas teorías es ciertamente relevante dentro de la sociología, hasta el punto de que ambos investigadores crearon dos centros de investigación específicos desde el que otros sociólogos han ido desarrollando sus trabajos bajo estas epistemologías, ampliándolas, reformulándolas y adaptándolas a una gran cantidad de temas e intereses distintos. Alfonso Pérez-Agote fundó en 1994 el Centro de Estudios sobre la Identidad Colectiva (CEIC) en la Universidad del País Vasco y Alain Touraine fundó en 1981 el Centro de Análisis y de Intervenciones Sociológicas (CADIS) en la Escuela de Altos Estudios de Ciencias Sociales de París.

En mi tesis doctoral (Álvarez-Benavides, 2013), dirigida por Alfonso Pérez-Agote y Michel Wieviorka, cofundador del CADIS y uno de los discípulos más reconocidos de Touraine, analicé los procesos de (re)construcción de la identidad colectiva de los migrantes marroquíes que, fruto de los procesos migratorios, se habían establecido en Madrid. El interés fundamental era comprender, a partir de una investigación cualitativa, las transformaciones identitarias que se producen durante el proceso migratorio, encuadradas además en el contexto de la globalización, en el que las identidades son cada vez más variables. Para ello decidí utilizar ambas perspectivas como soporte teórico y analítico que me permitiera abordar este fenómeno desde el individuo, como sujeto, como actor social, pero también como perteneciente a un colectivo.

El objetivo fundamental del texto no es otro que mostrar no solo la compatibilidad de ambas teorías, sino su utilidad para analizar procesos sociales tan complejos como las migraciones internacionales. Para ello se va a utilizar como soporte empírico fundamental mi tesis doctoral (Álvarez-Benavides, 2013), así como toda una serie de investigaciones propias o ajenas que han tenido alguna de estas dos perspectivas o ambas como marco teórico de referencia.

\section{LA IDENTIDAD COMO CATEGORÍA SOCIOLÓGICA}

Para investigar los procesos identitarios relacionados con los fenómenos migratorios debemos analizar cómo se construye la identidad a nivel individual y a nivel colectivo y cómo participan tanto los grupos de pertenencia (endogrupo) como los grupos de oposición (exogrupo) [Merton, 1949 (2002)]. La identidad colectiva ${ }^{1}{ }^{3}$ depende de la definición que nos damos a nosotros mismos como pertenecientes a un grupo determinado y como diferentes a otros. Incluso cuando no se produce un encuentro real entre individuos y colectivos, la construcción del yo se hace por oposición, a partir de elementos extraídos de la historia, del imaginario colectivo o de las nuevas informaciones, ideas, gustos, etc. La psicología social (Turner, 1990; Tajfel, 1984) nos ha enseñado que nos definimos en oposición a otras personas

\footnotetext{
${ }^{1}$ https://identidadcolectiva.es

2 http://cadis.ehess.fr

${ }^{3}$ El trabajo de campo de esta tesis se realizó entre 2005-2010, y consistió en 20 entrevistas en profundidad, 3 grupos de discusión, 10 historias de vida y 5 entrevistas colectivas.

Estudios de la Paz y el Conflicto, Revista Latinoamericana, IUDPAS-UNAH, Volumen 1, Número 1, enero-junio 2020, pp. 97-115. DOI: 10.5377/rlpc.v1i1.9518
} 
y a otros colectivos, por lo que la identidad colectiva es impensable al margen de la alteridad. En los contextos multiétnicos esta alteridad se refuerza a partir de la interacción social, por lo que en los espacios translocales van a surgir conflictos simbólicos o reales entre las distintas identificaciones colectivas y categorizaciones sociales.

Para Enrique Santamaría $(1994,2002)$ la sociedad de recepción considera al inmigrante como un individuo perteneciente a un grupo concreto, diferenciado y que, al pertenecer a ese grupo, porta toda una serie de características culturales, sociales y religiosas inseparables de su propia identidad. El inmigrante no comunitario se define por su pertenencia al grupo migrante (minoría étnica según Santamaría), nunca por su individualidad. Esa capacidad de identificarse individualmente le es negada, primero porque tiene que justificar su presencia en la sociedad, legitimándola a través de un trabajo y, segundo, porque pertenece a un grupo concreto que le define y le avoca a tener unas relaciones particulares y definidas previamente con el resto de la sociedad.

El proceso de construcción de esta identidad desde la sociedad de recepción es complejo y variable, especialmente cuando además de la definición apriorística ésta se refuerza a través de la interacción social. Esta categorización exógena no tiene por qué coincidir con la identidad propia del migrante, porque de hecho esto sólo ocurre en casos de asimilación total (Schnapper, 1990). Los migrantes articulan sus propias definiciones del yo, de los endogrupos y de los exogrupos, pero en la sociedad de recepción estas categorizaciones son menos poderosas que las de los nacionales.

La condición o definición del inmigrante como extraño impera en las sociedades occidentales articulando los discursos sociales, económicos y políticos sobre la diferencia, pero las ciencias sociales nos vienen mostrando desde hace varias décadas que ser inmigrante no es una característica inherente a ciertos individuos o colectivos, ni siquiera cuando éstos se desplazan y se instalan en países distintos a los que los vieron nacer, ser inmigrante es una categoría social. Es decir, la condición de inmigrante es una construcción social. No podemos extraer características, cualidades, estructuras reconocibles y veraces de dicha categoría. Ser inmigrante no conlleva una manera de ser, una cultura, un comportamiento colectivo, una identidad; el proceso de la configuración del inmigrante es complejo y contingente, depende de muchos factores, como quién construye esa categoría, en qué contexto la construye (espacial-temporal-histórico-político-cultural) y con qué intenciones (si es que hay intenciones). Ser diferente, en el caso de los inmigrantes, es una construcción relacional que se expresa cuando se llega a la sociedad de recepción, independientemente de que no se cumplan los estereotipos que parecen más obvios en la objetivación de los sujetos migrados.

Al mismo tiempo, en el contexto de la globalización la identidad es cada vez más compleja debido a la pluralidad de identificaciones posibles y a las situaciones de convivencia intercultural, en la que intervienen toda una serie de constricciones a la hora de autoidentificarnos e identificar a los demás. La globalización, que ha puesto en contacto a individuos que antes no sabían ni de su existencia mutua, ha posibilitado la creación de diásporas de colectivos que se han dispersado por el mundo, que migran más que inmigran y que hacen, de este modo, cada vez más variables y complejas las identidades, aunque todavía en algunos sectores parezcan homogéneas (Wieviorka, 2004: 23-24).

Para analizar los procesos de (re)construcción y de (re)formulación de la identidad colectiva de cualquier colectivo migrante, tanto en las primeras etapas del proceso migratorio como, incluso, con las segundas y terceras generaciones, necesitamos un marco teórico que dé cuenta de las contingencias propias del contexto global, las categorías sociales nacionales y locales, y las articulaciones propias de cada colectivo y de cada momento.

Estudios de la Paz y el Conflicto, Revista Latinoamericana, IUDPAS-UNAH, Volumen 1, Número 1, enero-junio 2020, pp. 97-115. DOI: 10.5377/rlpc.v1i1.9518 


\section{LA TEORÍA DE LA IDENTIDAD COLECTIVA}

Alfonso Pérez-Agote propuso en 1994 un modelo fenomenológico-genético para el análisis comparativo de la dimensión política de las identidades colectivas en el Estado de las autonomías. Según Pérez-Agote (1994: 308-309) a través de múltiples interacciones de la vida social los actores interiorizan maneras de definir la realidad social (y no social), y a través de esta interacción las definiciones se impregnan de afectividad. El modelo fenomenológico nos sirve para reconocer los elementos que los individuos utilizan para caracterizarse a ellos mismos. Los más habituales son el territorio y la historia (el espacio y el tiempo sagrados), y la lengua. Esto se debe a que toda identidad colectiva tiene que presentar alguna forma simbólica de comunicación y participación.

Tanto las redes formales como no formales son los lugares en los que se produce dicha comunicación y en los que se participa a través de los elementos que articularían el modelo fenomenológico. De esta manera Pérez-Agote (1994: 310) afirma que: "los actores, a la hora de diferenciarse de los otros, toman rasgos diferenciables para hacerlo, considerándolos como características propias de su grupo, o, lo que es más, considerando su identidad como la proyección subjetiva de ese rasgo pretendidamente objetivo. (...) Los actores utilizan rasgos objetivables. Es decir, que para ellos debe existir una frontera clara y visible, objetiva, de la identidad con respecto a los otros". Por un lado, cuando nos referimos a la construcción de la identidad la sociedad de recepción describe una serie de rasgos que pretender ser objetivos de la identidad autóctona, pero también de la identidad migrante. De la misma manera, los migrantes señalan ciertos rasgos que participan en la formación de la identidad colectiva, es decir, de su ser colectivo (independientemente de que éstos coincidan o no con la definición de la población autóctona -e, incluso, con la de otros migrantes pertenecientes a su mismo grupo étnico o nacionalidad-), que son (re)editados en la sociedad de recepción. Los actores definen su identidad colectiva haciendo llamada a características objetivas que, para ellos, van más allá de la posible existencia de conciencia de identidad.

Según Pérez-Agote (1994: 317-318) la fundación y el mantenimiento de la identidad colectiva tiene que ver con el paso generacional y con ciertos mecanismos sociales y sociológicos. Los elementos sociales se refieren a instituciones sociales claramente visibles y detectables (familia, grupos inter pares, sistema educativo, religión e iglesia, mundo asociativo, empresa, intelectuales, medios de comunicación y partidos políticos); los elementos sociológicos se refieren a un segundo nivel de abstracción pues son más bien procesos inferibles que instituciones detectables (sistemas de liderazgo y élites, relaciones intergeneracionales y el conflicto social).

Las redes tienen la capacidad de gestionar, en cierto modo, los ciclos migratorios, pero también dan cohesión grupal, es decir, que posibilitan la reedición de las costumbres y de aquellos elementos que configuran la identidad colectiva en un plano multidimensional. No solo son importantes para las cuestiones administrativas y relacionadas con la integración en la nueva sociedad (entendida en el sentido legal), sino que son lugares de reproducción y de producción de la identidad colectiva, en los que se habla de lo común, no solo de las dificultades, sino también de aspectos culturales, lúdicos, del día a día (García, Ramírez y Jariego, 2001). Los momentos de ocio, en los que se está con los amigos, con los familiares, pueden servir como válvula de escape para sentirse cómodo, entre pares, y en un contexto en que no entra en juego la dialéctica de la alteridad, muy especialmente en los primeros

Estudios de la Paz y el Conflicto, Revista Latinoamericana, IUDPAS-UNAH, Volumen 1, Número 1, enero-junio 2020, pp. 97-115. DOI: 10.5377/rlpc.v1i1.9518 
momentos de la inmigración. Pero, además, son momentos de afirmación, en los que uno recupera su forma de hablar, su manera de reírse, su forma de comportarse en público; en definitiva, costumbres que pueden no tener una relevancia social o sociológica aparentemente importante, pero que para los individuos se convierten en momentos de afirmación grupal, independientemente de la relación que se tenga con la sociedad de recepción (ÁlvarezBenavides, 2011, 2013: 161-203; Pérez-Agote, Tejerina y Barañano, 2010).

Con la globalización de las comunicaciones las redes de migrantes se han vuelto planetarias. La transformación de los espacios locales en espacios glocales hace que individuos totalmente alejados reconstruyan una identidad colectiva a partir de similitudes, no sólo culturales y relacionadas con el origen, sino articuladas también a partir de desafíos comunes que se presentan por el hecho de migrar a Occidente (Álvarez-Benavides, 2007, 2009). Los medios de comunicación de masas, centralizados principalmente en los locutorios, son lugares comunes de los migrantes y sus canales principales de comunicación con la familia. El uso de Internet, la video-llamada, etc., han supuesto una revolución en las relaciones familiares que se transforman en relaciones globales, formándose así las llamadas familias transnacionales (Parella, 2007) o las e-familias (Benítez, 2011). Sin embargo, a pesar de que son relaciones en la distancia, gracias a estas nuevas tecnologías el espacio y el tiempo se pliegan, dando lugar a relaciones cotidianas entre individuos que se encuentran a miles de kilómetros de distancia. El aquí y el allí, lo local y lo global se transforman, inevitablemente, a través de este contacto cotidiano. Estas relaciones diaspóricas son fundamentales para comprender las migraciones contemporáneas y las pautas de asentamiento e integración, como han mostrado una gran cantidad de estudios (Pérez-Agote, Tejerina y Barañano, 2010; Álvarez Miranda, 2007, 2009a; Arango, 2003)

Al igual que la familia, la religión es otro de los mecanismos fundamentales en la configuración de la identidad en contextos migratorios, especialmente cuando la religión mayoritaria no se corresponde con la del colectivo migrante (Pérez-Agote 2012; Pérez-Agote y Santiago, 2016, 2009). Los cultos y las celebraciones religiosas son uno de los elementos culturales que se revitalizan con más fuerza y rapidez. El trabajo de campo de mi tesis doctoral y otras investigaciones que se hicieron en Madrid a principios del cambio de milenio (Álvarez-Benavides, 2013: 242-247; Pérez-Agote, Tejerina y Barañano, 2010; ÁlvarezMiranda, 2009a), mostraron que dado que el proceso migratorio era reciente y que no había una comunidad numerosa previamente establecida, ante las dificultades de encontrar espacios propios, en el caso de los migrantes musulmanes, muchos de los ritos religiosos solían tener un carácter intercultural solapándose las diferencias dogmáticas entre las distintas interpretaciones del rito musulmán. La mezquita de la M30 de Madrid era el centro al que acudían la mayoría de los creyentes los días de celebración, aunque para el culto diario o eventual se acudían a mezquitas de diferentes colectivos étnicos y nacionales. En este caso primaría la identidad colectiva musulmana por encima de las diferencias interpretativas de unos grupos u otros.

La fiesta del cordero o el Ramadán se realizan en familia, en las casas y en núcleos grupales familiares o de amigos, es decir, en las redes. Son momentos de reunión, de sosiego, de aceptación, pero, además, de reproducción de las costumbres, de participar en lo común. La forma en que las cuestiones religiosas se adaptan al nuevo contexto es enormemente plural. Estos mismos procesos de adaptación han ido sucediendo en otros colectivos migrantes que han ido llegando a Madrid o otras partes de España, no solo musulmanes, sino también católicos, evangélicos, ortodoxos, protestantes, etc. (Montañés, 2015; Pérez-Agote y Santiago, 2016, 2009).

Estudios de la Paz y el Conflicto, Revista Latinoamericana, IUDPAS-UNAH, Volumen 1, Número 1, enero-junio 2020, pp. 97-115. DOI: $10.5377 /$ rlpc.v1i1.9518 
Las reivindicaciones de reconocimiento social, de posibilidad de reproducir ciertas costumbres, ciertas tradiciones, son una muestra de que los migrantes sienten esos elementos como una parte fundamental de sus vidas y de sus identidades. El proceso de adaptación pasa por distintas fases y una de ellas es la reivindicación de derechos civiles. En el caso español, tenemos ejemplos relacionados con la lengua, la cultura o la religión. Madres y padres que reclaman clases de árabe, polaco o cualquier otra lengua (Fernández-Saurez, Verdía y De Palma, 2018; Álvarez-Benavides, 2013: 196), o que se enseñe su religión en la escuela -musulmana, evangélica, ortodoxa- (Briones, 2018; Álvarez-Benavides, 2013: 197), o que se hagan menús especiales halal en los centros de trabajo y en los centros educativos, etc. (Álvarez-Benavides, 2013: 244). Estas reclamaciones de reconocimiento son especialmente importantes cuando se refieren a los hijos, ya que significa que los padres se resisten a la asimilación de sus descendientes, al querer que no pierdan sus costumbres. La lengua es un elemento muy reconocible en este sentido, no solo tiene que ver con la comunicación y con la cultura, sino también con la identidad y la cohesión grupal, como establece Pérez-Agote en su modelo fenomenológico-genético (1994). Uno de los aspectos fundamentales de la identidad colectiva es su reproducción intergeneracional, es decir, cómo esta identidad pasa de los padres a los hijos. Es por esto que muchos padres migrantes se preocupan de que sus hijos no pierdan su cultura de origen, es decir, que se asimilen a la cultura de recepción, que se "españolicen".

Hay, sin duda, un intento de conservar la cultura, que se plasma en muchos elementos identitarios que son importantes para el individuo y el colectivo, de ahí que la trasmisión de estos elementos a los hijos sea un aspecto central del proceso migratorio, sin embargo, este proceso tiene un carácter más productivo que reproductivo. Los trabajos de Joan Lacomba (2001, 2001a) sobre los inmigrantes musulmanes que llegaron a España a comienzos del milenio, mostraron cómo las prácticas religiosas se han readaptado al nuevo contexto, pero también las relaciones basadas en el género o en la edad. Estos mismos fenómenos han sido recogidos también por trabajos posteriores no solo en España (Pérez-Agote y Santiago, 2009), sino en otros países de Europa (Álvarez-Miranda, 2009) y en otros países como Argentina (Arduino, 2011) o Estados Unidos (Hirschman, 2006), por citar algunos ejemplos. En este sentido, Luis Abad, ya insistía hace casi tres décadas en que:

"La identidad colectiva de las minorías étnicas inmigrantes no es un reflejo especular de la de sus orígenes. Nunca reproducen fielmente sus culturas autóctonas. Las identidades étnicas se construyen y reconstruyen a partir del juego dinámico tanto de las condiciones reales de su existencia, como de los procesos cognitivos y afectivos con que se justifican y elaboran. La identidad étnica no es consecuencia del aislamiento, sino resultado de una estrategia en el curso de la cual las fronteras son continuamente redefinidas" (Abad, 1993:39).

Pero como toda identidad colectiva, la étnica tampoco es monolítica. Ni aquí ni allí. Por un lado, aunque se pretendiera una recreación total y fidedigna de la cultura, de la identidad, las inevitables mutaciones, adaptaciones, revisiones, contraposiciones, influencias harían que muchas de estas recreaciones fueran insostenibles en el nuevo contexto social. Por otro, el juego dialéctico de adaptación, (re)creación, situaciones relacionales como el género, la edad, o el origen étnico, también son contingentes en la sociedad de origen, antes, durante y después de proceso migratorio. Por lo tanto, y pesar de que desde fuera, desde la sociedad de recepción se tiende a homogeneizar a los migrantes por su lugar de procedencia, a dotarlos de una cultura sin fisiones y a distinguirlos y englobarlos a partir de estereotipos que son más o menos visibles, los individuos inmigrados se sienten y se muestran diferentes a otros

Estudios de la Paz y el Conflicto, Revista Latinoamericana, IUDPAS-UNAH, Volumen 1, Número 1, enero-junio 2020, pp. 97-115. DOI: 10.5377/rlpc.v1i1.9518 
individuos inmigrados de su misma procedencia o englobados en su mismo grupo étnico (Álvarez-Benavides, 2011; Garreta, 2003; Santamaría, 2002; Ben Jelloun, 1996). Estas diferencias van desde lo individual, esto es, la identidad propia, la diferenciación respecto a otros, hasta lo grupal, el sentirse perteneciente a un grupo que no es el que desde la sociedad de recepción se construye.

\section{LA TEORÍA DEL SUJETO Y DE LOS PROCESOS DE SUBJETIVACIÓN}

La teoría del sujeto de Touraine es una teoría de la acción (Touraine, 1965) y además una de las últimas teorías holísticas de la sociología. Aunque su articulación y difusión se relaciona principalmente con los "nuevos movimientos sociales" (Touraine, 1969), que para él son los que "producen la sociedad" (Touraine, 1973), su aplicación se extendió rápidamente a estudios sobre género, migraciones, etnia y raza, religión, etc. La base, como no podría ser de otra manera, es el sujeto, un sujeto que pretende reivindicarse haciéndose actor:

"No hay ningún otro punto de apoyo en un mundo en incontrolable y en continuo cambio que el esfuerzo del individuo en transformar sus experiencias vividas en la construcción de sí mismo como actor. Ese esfuerzo del individuo para ser actor es lo que yo llamo sujeto, que no se confunde ni con el conjunto de experiencias ni con un principio superior que guíe al individuo y le de una vocación. El sujeto no tiene otro contenido que la producción de sí mismo. No sirve a ninguna causa, ningún valor, ninguna ley que no sea su necesidad y su deseo de resistir por su propio desmembramiento en un universo en movimiento, sin orden y sin equilibrio" (Touraine, 1997: 28, traducción propia).

La complejidad hermenéutica de la teoría del sujeto es a su vez su gran logro, la capacidad de conjugar lo individual con lo colectivo, lo subjetivo con la acción social. Este tropo intelectual se lo debemos principalmente a Michel Wieviorka (2012), que, en un acierto interpretativo y pragmático, se centró más en la acción que en la ontología del sujeto, comenzando a utilizar la subjetivación y los procesos de subjetivación como herramienta analítica para aplicar la teoría de Touraine en distintos campos de la sociología.

A la sociología de las migraciones esta perspectiva le ofrece muchas posibilidades y plantea una dimensión crítica que despoja a la disciplina del paternalismo en el que algunas veces cae. Teniendo en cuenta el objeto de este texto, nos permite además dar un salto epistemológico, puesto que si limitamos el análisis de la recreación de la identidad colectiva a los procesos de reproducción parecería que los migrantes son sujetos pasivos que de una manera u otra intentan realizar sus prácticas culturales y religiosas como pueden, en pequeños grupos, en minorías, en el espacio que les permite la sociedad de recepción. Sin duda el etiquetaje étnico tiene un carácter racista y un peso determinante en las relaciones entre autóctonos y migrantes, pero no es ni mucho menos el único mecanismo que interviene en la identificación de los migrantes. Es necesario dar un paso más en el análisis, realizar este salto epistemológico, puesto que los inmigrantes, como sujetos, reclaman mucho más que pequeños espacios de libertad.

Uno de los problemas principales en los que ha caído la sociología de las migraciones ha sido tratar a los migrantes únicamente como víctimas. Muchas investigaciones han denunciado la marginalidad en la que se encuentra los colectivos migrantes, debido a situaciones de arbitrariedad y de injusticia social; se han analizado las distintas formas en las que se construye socialmente la diferencia y los distintos tipos de racismo que emanan de

Estudios de la Paz y el Conflicto, Revista Latinoamericana, IUDPAS-UNAH, Volumen 1, Número 1, enero-junio 2020, pp. 97-115. DOI: 10.5377/rlpc.v1i1.9518 
los medios de comunicación de masas y de las élites políticas y económicas; y también se ha visto cómo estos discursos son aceptados y puestos en práctica por una gran parte de la ciudadanía en la sociedad de recepción (Álvarez-Benavides, 2013: 211-235). Todo ello es fundamental ya que el científico social debe ser crítico y denunciar todas estas situaciones e indagar en los mecanismos sociales que las producen y reproducen, pero no se puede limitar a la denuncia. Si se reduce el análisis de las migraciones al racismo, en realidad, lo que se está haciendo, aunque sea sin intención o precisamente con la intención contraria, es lo mismo que hacen las esferas de poder que plantean la inmigración como problema. Si solo se denuncian las situaciones en las que los migrantes son marginados, aunque se propongan formas y medios para evitar estas situaciones, no se aborda la parte creativa de su inserción en las sociedades occidentales. En cierto modo, de esta manera, se justifican los discursos que afirman que los migrantes viven estas situaciones de marginalidad debido a que tienen una cultura inferior que no les permite avanzar socialmente. Se homogeneiza al migrante por su componente cultural tanto cuando se dice que ponen en peligro la identidad nacional por sus costumbres retrógradas, como cuando solo se denuncia su condición de víctima. Las dos actitudes son paternalistas y etnocéntricas, porque no se reconoce la capacidad del migrante para ser sujeto de su propia realidad.

El migrante sufre situaciones racistas y su posición en la sociedad de recepción es generalmente de inferioridad, pero existe todo un trabajo individual y colectivo para salir de estas situaciones. El simple hecho de migrar implica un reto y es, por tanto, un proceso de toma de conciencia del propio yo y un intento de mejorar una condición de vida previa. Inmigrar es un proceso de subjetivación en sí mismo. Es por esto que Wieviorka en su libro Neuf leçons de sociologie (2008), que aborda los retos contemporáneos de las ciencias sociales, afirma que el sociólogo debe investigar las migraciones “(...) desde la perspectiva de su creatividad y no solamente desde su pobreza y sus dificultades" (Wieviorka, 2008: 63, traducción propia).

Ese proceso debe partir del reconocimiento de la capacidad del migrante de ser sujeto y analizar así los procesos de subjetivación que se llevan a cabo durante las migraciones y que conllevan, sin duda, transformaciones en la identidad. Touraine ha insistido durante toda su producción académica en la necesidad de considerar a los individuos como sujetos, recalcando su libertad individual y su deseo de ser actores de su propia vida, evidentemente entre estos individuos y colectivos están los migrantes. Recordemos la definición de sujeto de Touranie:

"Llamo sujeto a la construcción del individuo (o del grupo) como actor, por la asociación de su libertad afirmada y su experiencia vivida asumida y reinterpretada. El sujeto es el esfuerzo de transformar una situación vivida en acción libre, introduce la libertad en lo que en principio parecen determinantes sociales y herencia cultural" (Touraine, 1994: 23-24, traducción propia).

El error de homogeneizar a un sujeto individual o colectivo dentro de una identidad determinada por una cultura, religión o colectivo no se produce exclusivamente por un determinismo ideológico, sino que puede estar condicionado por la posición del investigador social respecto al sujeto o al colectivo investigado, por lo que tanto el tratamiento del migrante como enemigo o como víctima, supone la negación de la capacidad del individuo de ser sujeto. Esto mismo sucede cuando se plantea la reconstrucción de la identidad o de las prácticas culturales en la sociedad de recepción como una recreación lo más fidedigna posible de lo adquirido durante la socialización primaria. Es cierto que los migrantes intentan recrear su cultura, su identidad y realizar sus prácticas sociales tradicionales en el nuevo contexto, 
pero también hay un proceso claro de producción y de adaptación, en el que estas prácticas se amoldan a la nueva realidad y en el que también surgen formas creativas de producción de la identidad individual y colectiva, así como de inserción social. Como expresa Wieviorka: "A la absorción del migrante en el seno de una cultura homogénea de las industrias culturales de masas, también se acompaña de la reproducción de formas culturales y religiosas y además de la producción de nuevas formas culturales, vinculadas a los flujos, a las circulaciones, a la desterritorialización, a la movilidad" (Wieviorka, 2008: 63, traducción propia).

\section{SUBJETIVACIÓN Y (RE)PRODUCCIÓN DE LA IDENTIDAD COLECTIVA}

Desde el punto de vista espacial, cuando nos referimos a los procesos migratorios, las redes son esenciales para comprender los avatares de la identidad colectiva, puesto que su construcción, reconstrucción, formulación y reformulación no se produce a partir, solamente, de referentes en el allí o en el aquí. Como han mostrado los estudios migratorios desde sus inicios, a principios de Siglo XX (Thomas y Znaniecki, 2004), las redes son fundamentales a la hora de decidir iniciar un proyecto migratorio, elegir el sitio de residencia, encontrar una vivienda y un trabajo, regularizar la situación administrativa, además de para mantener un contacto con el allí y una manera de seguir conectado con lo/s tuyo/s. Analizar todos estos procesos nos ayuda a comprender cómo se articula una identidad colectiva en un espacio determinado, un barrio, una ciudad o un país. El modelo fenomenológico genético nos permite, como decíamos, identificar los momentos, lugares y procesos de reconstrucción, reafirmación y reproducción de la identidad colectiva. Sin embargo, en el contexto de la globalización de las comunicaciones, el contacto con la familia ahora constante e instantáneo, al igual que con otros compatriotas dispersados por Europa y por otras partes del mundo, las redes se plurifican, del mismo modo que la información que cada sujeto recibe, a través de los grandes medios de comunicación globales y a través de la que cada individuo que migra genera.

Los medios de comunicación de masas han fomentado una imagen específica de estas redes, que en el contexto de la globalización se ha generalizado. A pesar de que muchos periodistas y comunicadores han tratado de matizar los discursos negativos relacionados con las migraciones, inevitablemente las imágenes desfavorables sobre éstas persisten, y la utilización de un leguaje específico asociado a los procesos migratorios es un elemento configurador esencial que categoriza el fenómeno. En el caso de la inmigración desde el continente africano hacia Europa, las metáforas acuosas, como oleadas de inmigrantes, avalanchas de inmigrantes, han sido metáforas clásicas (Retis, 2007: 23-26;), lo que, como se señalaba más arriba, repercute inevitablemente en la imagen y en la identidad que la sociedad de recepción produce de los colectivos migrantes. Otro referente tradicional es la ilegalidad, la clandestinidad de las migraciones, ya sea para asociar la inmigración con el crimen y con la delincuencia o, desde ciertas posiciones más paternalistas e incluso piadosas, identificar a todos los migrantes y sus redes, con las imágenes de aquéllos que de manera lamentable llegan a través del mar o mueren en el intento. Michel Peraldi y Ahlame Rahmi han analizado en profundidad las complejas redes entre Marruecos y occidente, así como entre Marruecos y otros países africanos, siendo éstas uno de los ejemplos clásicos de la construcción negativa de las migraciones. Precisamente el interés de Peraldi ha sido mostrar que las migraciones desde Marruecos tienen una dimensión mucho más compleja de lo que generalmente se muestra desde las esferas políticas y a través de los medios de comunicación

Estudios de la Paz y el Conflicto, Revista Latinoamericana, IUDPAS-UNAH, Volumen 1, Número 1, enero-junio 2020, pp. 97-115. DOI: 10.5377/rlpc.v1i1.9518 
de masas, tanto en Occidente como en el propio Marruecos. Según Peraldi y Rahmi, la inmigración solo se plantea en términos de clandestinidad, una representación que él denomina "paterisme" (paterismo): "una visión que combina lástima y estigmatización sobre la base de una imagen exclusivamente policial, incluso criminal, de los movimientos migratorios, que centra la imagen y la reflexión sobre "los pasajeros" clandestinos que van hacia Europa, en detrimento de las formas dinámicas de circulación entre el Magreb, África y Europa" (Peraldi y Rahmi, 2007: 67, trarucción propia). Esta visión de las migraciones no solo produce efectos de rechazo y de culpabilización de los migrantes en las sociedades de recepción, sino que desde el punto de vista de las ciencias sociales deja de lado toda una serie de procesos que explican la complejidad de las migraciones contemporáneas. Ya no podemos pensar en las migraciones en los términos en los que lo hacía Simmel, partir de un sitio para establecerse en otro, sino que es en la propia circularidad de los ciclos migratorios, en los espacios transnacionales, que introducen la dimensión local y global, donde debemos centrar nuestro análisis (Peraldi y Rahmi, 2007: 70).

En estos espacios transnacionales la creatividad juega un papel central, que va mucho más allá de la reproducción de los referentes premigratorios y que posibilita nuevas formas de inserción y participación social. Alain Tarrius, en su famoso libro La mundialización por abajo (2007), mostró todo el entramado de redes que han sobrepasado la dimensión del Estado-nación y que han creado una mundialización por lo bajo a lo largo del mediterráneo occidental. Estas redes también han transformado los ciclos migratorios volviéndolos circulares, retroalimentativos, al igual que a los migrantes y las maneras en las que se identifican. La identidad de los migrantes ahora está condicionada por su "capacidad circulatoria", es decir, por su capacidad de manejarse y moverse a través de esas redes, una capacidad inédita de ser de aquí, de allá, y de aquí y de allá a la vez (que) sustituye la antigua oposición entre ser de aquí o bien ser de allá (Tarrius, 2007: 29).

Esa capacidad de adaptarse a las nuevas realidades espaciotemporales se traduce en distintos tipos de subjetivaciones. En el caso que trabaja Tarrius es a través del comercio, de todo tipo, por la costa mediterránea occidental. Las redes comerciales que crean los propios migrantes se introducen de pleno en la globalización económica que dicta, aparentemente, las reglas del mercado. En estas redes los migrantes no son sujetos pasivos en situaciones de marginalidad, aunque muchas veces la migración se produzca bajo estas condiciones, sino "hormigas" que mercadean con productos y que globalizan sus redes comerciales a través de mecanismos aceptados colectivamente distintos a los de los mercados formales. Todo ello ha generado lazos comerciales y un espacio económico transnacional entre el aquí y el allá (Peraldi y Rhami, 2007: 72).

Las cuestiones laborales son otro de los aspectos más importantes en los estudios migratorios, que más condicionan los procesos de migración y de integración, y que generan más conflictos con la sociedad de recepción, por lo que desde el punto de vista de la teoría de la acción (Touraine, 1965) y, al igual que ocurría en otros ámbitos donde se producen prácticas racistas, resulta más beneficioso analíticamente abordar estos procesos desde la óptica de la subjetivación de los colectivos migrantes que desde la victimización. Wieviorka insiste en que el investigador social no debe limitarse a denunciar las malas condiciones de trabajo de los migrantes o de los individuos, para analizar también las formas creativas y los procesos de subjetivación a través del trabajo:

"Introducir la perspectiva del sujeto en el análisis del trabajo no puede por tanto limitarse a considerar la alienación y la destrucción de los individuos. También debe interesarse por las dimensiones de autorrealización y creatividad, que significa, o puede significar, por lo tanto, no

Estudios de la Paz y el Conflicto, Revista Latinoamericana, IUDPAS-UNAH, Volumen 1, Número 1, enero-junio 2020, pp. 97-115. DOI: 10.5377/rlpc.v1i1.9518 
perder de vista los enfoques iniciados por Hegel o Marx" (Wieviorka, 2008: 28, traducción propia).

La característica fundamental de las ciudades globales, en el sentido en el que lo plantea Saskia Sassen (1999), es que además de concentrar y conectar las grandes redes financieras, comerciales y de información de la globalización, controladas por las grandes esferas de poder, también se caracterizan por ser cada vez más multiculturales, y por tener esas redes "por abajo", redes de migrantes que se conectan, que intercambian información y que comercian. Esas redes son espacialmente palpables en barrios como Lavapiés en Madrid (Álvarez-Benavides, 2007, 2009), Ciutat Vella en Barcelona, Harlem o el Bronx en Nueva York, insertadas en otro tipo de redes globales, en las que se percibe la globalización tanto por arriba como por abajo. Además de las redes informales que buscan ayudar y beneficiar a los compatriotas, existen redes comerciales cuyo objetivo es el beneficio individual. Los migrantes han sabido rellenar el nicho comercial que surte de productos "étnicos" a los nuevos vecinos, pero también a los nacionales. Lo étnico, en muchos de estos barrios, se ha vuelto un reclamo comercial, incluso turístico, ya que los negocios que iban dirigidos a abastecer a las poblaciones migrantes son ya utilizados en la misma medida por población nacional (Riesco, 2003, 2010).

Si las redes y el comercio, se transforman debido a los fenómenos de alta movilidad y de comunicación globalizada estos cambios también afectan a la formación de la cultura y de la religión. En este sentido también habría que hablar de producción más que de reproducción, como de nuevo afirma Michel Wieviorka (2008: 21, traducción propia):

"Los investigadores que estudian los fenómenos religiosos señalan que los propios actores explican su fe como una decisión personal muy subjetiva (...), y no como una herencia, la simple reproducción de la religión de los padres y antepasados. (...) Las identidades culturales y religiosas (...) se producen, más que se reproducen. Son la expresión colectiva de elecciones personales, que se agregan, actúan, utilizando un vocabulario clásico, como «logro» personal, como autorrealización, más que como adscripción, determinación por imputación de una identidad determinada".

Efectivamente, la formación de la religión en los contextos migratorios no se traduce por una reedición de la religión de los padres o de los abuelos (Roy, 2006). La religión se vuelve una elección personal, subjetiva, y si existen casos en los que esta reconstrucción toma formas reactivas, también existen otros, la mayoría, en los que se hace un ejercicio de adaptación y de revisión de las creencias y prácticas religiosas que llevan al sujeto a adaptar y (re)formular lo adquirido. Lo religioso no solo produce conflictos con la sociedad de recepción, sino que también se dan encuentros entre creencias, comunicaciones, trasvases, que van desde lo cultural a lo específicamente religioso, un proceso recurrente en la historia de las religiones, pero que en nuestros días produce todo un abanico de nuevas formas de entender, practicar y gestionar las creencias a partir de la reflexividad y la negociación (Álvarez-Benavides, 2013).

En el ejemplo que se está utilizando durante todo el texto de la comunidad marroquí en España, es evidente que las transformaciones religiosas se producen en los dos lados y en el conjunto de redes reales y virtuales. Los marroquíes en España, en Marruecos, al igual que el conjunto de los musulmanes, tienen una concepción de lo religioso plural, variable y contingente, como el resto de los creyentes y de las creencias religiosas. La homogeneización del islam es una construcción moderna y occidental, aunque también haya corrientes

Estudios de la Paz y el Conflicto, Revista Latinoamericana, IUDPAS-UNAH, Volumen 1, Número 1, enero-junio 2020, pp. 97-115. DOI: 10.5377/rlpc.v1i1.9518 
religiosas y políticas en Oriente que pretenden homogeneizar estas creencias. En los contextos migratorios esta construcción homogénea es simplemente una forma de relacionarnos con los migrantes y de dar una supuesta coherencia a nuestra identidad autóctona. Si la identidad colectiva no es homogénea, tampoco lo es la pertenencia religiosa, ni en el lugar de origen ni en la sociedad de recepción, la forma de entender la religión es evidentemente plural (Álvarez-Benavides, 2011, 2011a)

Como hemos ido señalando, todas las categorías sociales son contingentes cuando nos referimos a los procesos de reconstrucción de la identidad colectiva en contextos migratorios y todas ellas pueden generar estigmas por parte de la sociedad de recepción, pero como nos muestra el modelo fenomenológico genético y la teoría del sujeto el proceso es mucho más complejo y menos determinista de lo que muchas veces se ha planteado desde la sociología $\mathrm{y}$, concretamente, desde los estudios migratorios.

Dentro de todas las categorías sociales destaca el género y, por ende, en los estudios migratorios su análisis debe hacerse de manera transversal al resto de categorías, tanto para señalar los conflictos en las relaciones entre autóctonos y migrantes, como para visibilizar los procesos creativos de gestión del proceso migratorio y de la (re)formulación de las identidades

Los estudios migratorios han mostrado cómo las mujeres migrantes sufren especialmente la discriminación por parte de la sociedad de recepción. Sonia Parella en su tesis doctoral y después en un libro (2003) ha analizado cómo la mujer inmigrante es discriminada a nivel laboral por ser mujer (discriminación por género), cobrando menos dinero y con situaciones laborales precarias; por realizar trabajos de baja cualificación (discriminación por clase social), como es el caso de la mujer empleada del hogar o de las limpiadoras; y por ser inmigrante (discriminación étnica). El punto de partida también puede ser otro, como las cuestiones religiosas, al ser mujeres están sometidas a las imposiciones del hombre (discriminación por género); sus prácticas religiosas como llevar velo son nocivas para la sociedad de recepción (discriminación étnica); y asumen su cultura sin cuestionársela debido a su baja formación (discriminación por clase social).

La discriminación y estigmatización de la mujer migrante se articula, por tanto, como una serie de muñecas rusas en las que, según el contexto, la sociedad, la cultura y la religión mayoritaria, unas capas se superpondrán sobre otras y unas serán más visibles que otras. En el contexto español, en el europeo y, en general, en el occidental, hay ciertas visibilidades y ciertos prejuicios que se relacionan especialmente con las mujeres musulmanas (ÁlvarezBenavides, 2011a). De manera paternalista, se homogeneiza a todas las mujeres dentro de una cultura y una religión, creada desde fuera, en la que se destacan ciertas características especialmente reprobables de algunas prácticas minoritarias, que además pueden tener un origen cultural y no religioso, o que son análogas en otras culturas o religiones, como la violencia machista, la ablación del clítoris o los abusos a menores. A la mujer migrante se le niega su capacidad de ser sujeto de su propia realidad cultural y religiosa y se le acusa, a la vez, de ser la responsable de su situación de vulnerabilidad y marginalidad, esto es, es la religión, las creencias, la cultura que has elegido, la que asumes sin cuestionarla, la que te oprime y te niega.

Lo que esconden las prácticas discriminatorias que viven las mujeres migrantes es en realidad la situación de inferioridad que experimentan las mujeres en general respecto a los hombres, pero esto no tiene que ver con su religión, sino con el hecho de ser mujer. El velo es uno de los marcadores identitarios que genera más conflicto en occidente, pero que refleja claramente que aunque la discriminación tiene, al menos, dos niveles, dos capas -ser

Estudios de la Paz y el Conflicto, Revista Latinoamericana, IUDPAS-UNAH, Volumen 1, Número 1, enero-junio 2020, pp. 97-115. DOI: 10.5377/rlpc.v1i1.9518 
musulmana y ser mujer-, es el género lo que articula el resto de discriminaciones. Si se es musulmana y negra, puede destacar primero el color, si se es musulmana y asiática, pueden ser los rasgos étnicos, o si se es musulmana pero blanca, puede ser una prenda, un símbolo religioso, como el velo. Sin embargo, ser mujer, como decíamos, es el elemento transversal a cualquier otra categorización, aunque la distinción se construya también sobre el color, el cuerpo, los rasgos étnicos o la ropa (Álvarez-Benavides, 2011a).

Cuando nos referimos al velo y a su prohibición en favor de la liberación de la mujer de una religión machista, lo que se está haciendo es, en realidad, utilizar una excusa patriarcal que, aunque se fundamenta en una práctica religiosa, tiene inevitablemente una lectura de género (de Botton et al 2004). Muchos de los argumentos para prohibir la utilización del velo pivotan en torno a la supuesta liberación de la mujer, ya que éste es un símbolo de opresión patriarcal, porque las chicas son obligadas a llevarlo. Sin embargo, como han mostrado muchas investigaciones en distintos contextos como el español (Álvarez-Benavides, 2011a), el inglés (Joly, 2017) o el italiano (Maddanu, 2013) son las propias mujeres veladas las que contestan estas afirmaciones, las que hacen del uso del velo algo personal. El velo tiene muchas interpretaciones por parte de las mujeres que lo llevan, puede ser un símbolo religioso, pero también un símbolo cultural, una suerte de patrimonio heredado (Roy, 2006), que quiere reproducirse como una afirmación de una identidad que se siente perdida, en peligro o cuestionada, como han mostrado los trabajos de Gaspard y Khosrokhavar (1995) en Francia, y de la misma manera que en ocasiones son forzadas a llevarlo, también en otras son presionadas para no hacerlo (Álvarez-Benavides, 2012).

El fundamentalismo y la irreflexibidad que muchas veces se achaca a las mujeres musulmanas reposa en los mismos preceptos patriarcales que pretenden prohibirles la utilización del velo. La variablidad de los usos del velo, de quiénes lo usan y cuándo, es mucho más abierta de lo que algunos pretenden mostrar (Aixelà, 2012). No hace falta hacer un gran esfuerzo etnográfico para encontrar mujeres que llevan velo y otras no y que son de la misma familia, hermanas, madres e hijas. El velo puede representar muchas cosas, es un símbolo susceptible de adquirir distintos significados dependiendo de la mujer que lo lleve. Puede utilizarse como un elemento cultural, político, incluso estético (Moreras, 2008). El peso de llevar el hiyad en occidente tiene necesariamente un elemento reflexivo, por lo que puede convertirse en un acto de afirmación.

Desde la perspectiva de la teoría del sujeto y de los procesos de subjetivación, la religión se reivindica, no la religión que les homogeneiza, ni la que articula la sociedad de recepción, ni tampoco la que reivindican otros individuos que pertenecen, supuestamente, al mismo colectivo religioso, sino la religión que les hace actoras capaces de decidir sobre sus creencias. Si la visibilidad, como decía, tiene muchos reprises, no son pocas las mujeres que quieren ser visibles a partir, precisamente, de una nueva articulación de lo que para otros es un estigma, ya sea a través del velo (Álvarez-Benavides, 2017; Khosrokhavar, 2003; Tietze, 2003; Guénif, 2003), de cualquier otro símbolo religioso o de cualquier otro elemento que se considere como parte importante de un ser colectivo interpretado y afirmado de manera personal. La historia de la sociología y de los movimientos sociales, que desde la perspectiva de Touraine es la misma (Pleyers y Álvarez-Benavides, 2019), nos ha mostrado cómo, precisamente, del estigma surge muchas veces la transformación social cuando se pretende reivindicar y afirmar una visibilidad negada en el espacio público.

En el fondo es una muestra más de que las mujeres van, ellas mismas, ocupando plazas y posiciones nuevas, se van empoderando, también las musulmanas y las marroquíes (Joly, 2017; Maddanu, 2013). Las transformaciones no se limitan al contexto de recepción, ni a lo

Estudios de la Paz y el Conflicto, Revista Latinoamericana, IUDPAS-UNAH, Volumen 1, Número 1, enero-junio 2020, pp. 97-115. DOI: 10.5377/rlpc.v1i1.9518 
individual, puesto que de manera directa o indirecta su sociedad de origen también se transforma porque esas maneras subjetivas de entender la religión y la cultura, que existen y se producen aquí y allá, se retroalimentan. Los migrantes no son sujetos pasivos y son las propias mujeres, también las migrantes, las que sin necesidad de una intervención desde fuera están transformando el patriarcado, su propia realidad, convirtiéndose en los sujetos que deciden cómo poner en práctica su religión en el nuevo contexto y ante los nuevos retos que se les presentan, visibilizándose ellas y también otras compatriotas, otras mujeres (ÁlvarezBenavides, 2017; 2011a).

\section{CONCLUSIONES}

La construcción y reconstrucción de la identidad individual y colectiva es uno de los aspectos fundamentales de las ciencias sociales en la era global. El debate en torno al individualismo y al comunitarismo se alimenta de los flujos migratorios, pero también de las realidades nacionales. Por un lado, el individuo tiende a cerrarse cada vez más sobre sí mismo, renunciando a lo social, a lo comunitario; la sociedad de la información nos conecta, pero también nos aísla. Por otro lado, esa misma sociedad global nos homogeniza, como afirman algunos teóricos de la globalización (Jameson, 1996; Anderson, 2000), a través de la extensión de un modelo y unas pautas culturales concretas que hacen desaparecer los particularismos de las distintas sociedades. Es cierto que esto es una parte de la globalización o un deseo del neoliberalismo, pero la globalización ha provocado otro tipo de sucesos sociales que además nacen con el mismo proceso mundializador. Así, una de las características principales de la globalización ha sido el despertar de nuevas identidades y de nuevas reclamaciones colectivas $\mathrm{y}$, por tanto, de nuevas formas de contestación.

La sociología del sujeto nos permite profundizar en los procesos de reconstrucción de la identidad individual y comprender sus implicaciones colectivas. Ser sujeto no significa renunciar a lo colectivo, sino interpelarlo desde el punto de vista de lo que para uno mismo es relevante. En contextos migratorios se puede sentir la pertenencia al colectivo migrante no en los términos en los que se construye esa identidad desde la sociedad de recepción, sino en los elementos culturales, religiosos, étnicos que el actor social considera importantes. La religión, la cultura, las tradiciones se reeditan, pero lejos de tender a la homogeneidad, son interpretados de una manera subjetiva. La participación en lo colectivo también tiene que ver con la idea de sujeto, puesto que no implica salir de la vida social, sino encontrar en ella las condiciones de realización de uno mismo, su autonomía. Lo mismo sucede con las sociedades de recepción, que son per se heterogéneas, poliédricas, diversas, cambiantes, fluidas y contingentes.

Una de las formas más evidentes de subjetivación es, precisamente, reconstruir una identidad colectiva y reclamarla como viable, como legítima, en la sociedad de recepción. Ambas perspectivas nos permiten ver y entender respuestas a la dominación. Cuando nos referimos, por ejemplo, al caso de los marroquíes que han migrado a España o a Europa, existe una identidad colectiva que está en continua formación y reformulación, a partir de las experiencias subjetivas, pero también de los contactos e intercambios continuos con los compatriotas. Esta identidad es nueva, pero se fragua a partir de elementos tradicionales y de las nuevas realidades locales y transnacionales. Es una identidad elegida. La identidad colectiva al igual que los mecanismos de integración social surgen a partir de definiciones, recorridos y experiencias individuales que tienen necesariamente un correlato en lo colectivo.

Estudios de la Paz y el Conflicto, Revista Latinoamericana, IUDPAS-UNAH, Volumen 1, Número 1, enero-junio 2020, pp. 97-115. DOI: 10.5377/rlpc.v1i1.9518 
No hay una renuncia hacia la identidad colectiva, sino una nueva producción de ésta a través de muchos tipos de subjetivaciones.

\section{REFERENCIAS}

Abad Márquez, L. (1993). "Nuevas formas de inmigración: un análisis de las relaciones interétnicas", Política y Sociedad, N. 12, 45-59.

Aixelà, Y. (2012). "La presentación social del cuerpo marroquí en contextos migratorios. Entre la afirmación identitaria y el rechazo islamófobo", Revista de Dialectología y Tradiciones Populares, N. 67, Vol. 1, 19-48.

Alvarez-Benavides, A. (2007). "Encuentros y desencuentros en el espacio urbano", V Congreso de Inmigración. Migraciones y Desarrollo Humano, 21 al 24 de marzo de 2007: Valencia.

Álvarez-Benavides, A. (2009). "Cruce de caminos: tiempos, espacios e identidades que se transforman. El caso del barrio de lavapiés en Madrid”. En Montoro, C., López, D, Pons, J.J. y Barcenilla, (Eds.). La inmigración internacional: motor de cambios sociodemográficos y territoriales. Navarra: Eunsa, 83-91.

Álvarez-Benavides, A. (2011). "Marocains à Madrid. Visibilité et invisibilité dans un espace global et local'. En Bourqia, R. (Ed.). Territoires, localité et globalité. Faits et effets de la mondialisation. Tome 2, París: L'Harmattan, 79-94.

Álvarez-Benavides, A. (2011a). "Femmes marocaines à Lavapiés (Madrid). La visibilité et l'invisibilité dans un espace global et local', Monográfico Femmes en Migration. Travail, Bizness, Exil, Asile, Revista NAQD, N.28, 201-212.

Álvarez-Benavides, A. (2013). "Procesos intergeneracionales de integración/marginalización y de (re)articulación de la identidad colectiva. Aplicación al caso de la inmigración marroquí en la Comunidad Autónoma de Madrid”. Tesis Doctoral inédita, Universidad Complutense de Madrid, Madrid. Disponible en: http://eprints.ucm.es/20040/1/T34317.pdf.

Álvarez-Benavides, A. (2017). "Processus d'intégration des migrants en Espagne". En Boucher, M., Pleyers, G., y Rabughin, P. (Dir.). Penser le sujet dans une société globale. París: Editions de la Maison des Sciences de 1'Homme, 239-250.

Álvarez-Miranda, B. (2009). "La acomodación del culto islámico en España. Comparación con Gran Bretaña, Alemania y Francia”. En Zapata-Barrero, R. (Ed.). Políticas de gobernabilidad de la inmigración en España. Barcelona: Ariel.

Álvarez-Miranda, B. (2009a). "Las identidades nacionales y transnacionales de los inmigrantes musulmanes en Europa", Revista del Ministerio de Trabajo y de Inmigración, N. $80,133-150$.

Anderson, P. (2000). Los orígenes de la postmodernidad. Barcelona: Anagramas.

Arango, J. (2003). "La explicación teórica de las migraciones luz y sombra". Migración y Desarrollo, N. 1, octubre. (Disponible online: http://rimd.reduaz.mx/revista/rev1/JoaquinArango.pdf).

Arduino, E. (2011). "Resignificación religiosa de inmigrantes senegaleses musulmanes en buenos aires actual", Magriberia, N. 4, 185-197.

Ben Jelloun, T. (1996). Ellos y nosotros, nosotros y los otros: Occidente y el Islam. Madrid: Casa de América.

Estudios de la Paz y el Conflicto, Revista Latinoamericana, IUDPAS-UNAH, Volumen 1, Número 1, enero-junio 2020, pp. 97-115. DOI: 10.5377/rlpc.v1i1.9518 
Benítez, J.L. (2011). La comunicación transnacional de las familias e-migrantes. San Salvador: PNUD/UCA.

Berger, P., Luckman, T. (1999). La construcción social de la realidad. Buenos Aires: Amorrortu.

Briones, R. (2018). "Religiones e inmigración en la España actual. Análisis de los cambios en el campo religioso", Gazeta de Antropología, N. 34, Vol. 2. (Disponible online: https://digibug.ugr.es/bitstream/handle/10481/54713/G34-2 05. RafaelBrionesGomez.pdf? sequence $=1 \&$ isAllowed $=\mathrm{y}$ ).

Conti, B. (2012). "L'émergence de l'islam dans l'espace public", Archives de sciences sociales des religions, N. 158, 119-136. (Disponible online: http://journals.openedition.org/assr/23885).

Fernández-Suárez, B., Verdía Varela, V. y Depalma, R. (2018). “Asociacionismo inmigrante en Galicia. Demandas desde la precariedad”, Papers. Revista de Sociologia, Vol.103, N. 4, 661-683.

García, M., Ramírez, M. y Jariego, I. (2001). "Una tipología analítica de las redes de apoyo social en inmigrantes africanos en Andalucía”, Revista Española de Investigaciones Sociológicas, N. 95, 99-125.

Garreta Bochaca, J. (2003). La integración sociocultural de las minorías étnicas (gitanos e inmigrantes). Barcelona: Anthropos.

Gaspard, F. y Khosrokhavar, F. (1995). Le foulard et la République. París: La Découverte.

Guénif Souilamas, N. (2003). Des "beurettes" aux descendantes d'immigrantsnordafricains. París: Grasset/Le Monde.

Hirschman, C. (2006). "El papel de la religión en los orígenes y la adaptación de los grupos de inmigrantes en Estados Unidos". En Portes A. y DeWind, J. (Coords.). Repesando las migraciones. Nuevas Perspectivas teóricas y empíricas. México: INM-UAZ, 411-440.

Jameson, F (1996). Teoría de la postmodernidad. Madrid: Trotta.

Joly, D. (2017). "Women from Muslim Communities: Autonomy and Capacity of Action", Sociology, N. 51, Vol. 4, 816-832.

Khosrokhavar, F. (2003). L'islam des jeunes. París: Flammarion.

Lacomba, J. (2001). "Inmigrantes senegaleses, islam y cofradías", Revista Internacional de Sociología, N. 29, 163-187.

Lacomba, J. (2001a). El Islam inmigrado. Transformaciones y adaptaciones de las prácticas religiosas. Madrid: Secretaría General Técnica.

Maddanu, S. (2013). Musulmans européens en mouvement: Pratiques et expériences quotidiennes chez les jeunes musulmans italiens. Perpignan: Halpha.

Merton, R.K [1949 (2002)]. Teoría y estructuras sociales. México: Fondo de cultura económica.

Montañés, A. (2015). "Interacciones entre cultura(s) y religión en minorías socio-religiosas: El caso de los musulmanes y evangélicos-pentecostales en España", Papeles del CEIC, 3, N. 15, 1-28.

Moreras, J. (2008). Simbologies en l'espai públic. Els debats sobre l'ús del hijab a Europa. Barcelona: Fundació Jaume Bofill.

Parella, S. (2007). "Los vínculos afectivos y de cuidado en las familias transnacionales. Migrantes Ecuatorianos y peruanos en España”, Migraciones Internacionales, N. 4, Vol. 2), 151-188.

Parella, S. (2003). Mujer, inmigrante y trabajadora: la triple discriminación. Barcelona: Antrophos.

Estudios de la Paz y el Conflicto, Revista Latinoamericana, IUDPAS-UNAH, Volumen 1, Número 1, enero-junio 2020, pp. 97-115. DOI: 10.5377/rlpc.v1i1.9518 
Peraldi, M. y Rahmi, A. (2007): "Des "pateras" au transnationalisme. Formes sociales et image politique des mouvements migratoires au Maroc", Hommes \& Migrations, N. 1266, 66-80.

Pérez-Agote Poveda, A. (1994). "Modelo fenomenológico-genético para el análisis comparativo de la dimensión política de las identidades colectivas en el estado de las autonomías". En VV.AA: Nationalims in Europe. Past an Present, Actas de Congreso Internacional os Nacionalismos en Europa. Pasado e Presente: Santiago de Compostela, 307-323.

Pérez-Agote, A. (2012). "Cuestiones suscitadas por la nueva pluralidad cultural y religiosa". En Tezanos, J.F. (Ed.). / XII Foro sobre Tendencias Sociales. Madrid: Editorial Sistema, 69-97.

Pérez-Agote, A. y Santiago, J. (2009). La nueva pluralidad religiosa. Madrid: Ministerio de Justicia.

Pérez-Agote, A. y Santiago, J. (2016). "Viejas y nuevas intersecciones entre religión e identidad: hacia un marco analítico", Papeles del CEIC, N. 2, 1-15.

Pérez-Agote, A., Tejerina, B., y Barañano, M. (Eds.) (2010). Barrios multiculturales: relaciones interétnicas en los Barrios de San Francisco (Bilbao) y Embajadores/Lavapiés (Madrid). Madrid: Trotta.

Pleyers, G. y Álvarez-Benavides, A. (2019). "La producción de la sociedad a través de los movimientos sociales", Revista de Estudios Sociolígicos, N. 28, Vol. 1, 141-149.

Retis, J. (Coord.) (2007). Inmigración y medios de comunicación. Aproximaciones y propuestas para las buenas prácticas periodísticas. Madrid: Ministerio de Trabajo y Asuntos Sociales.

Roy, O. (2006). El Islam en Europa: ¿una religión más o una cultura diferente?. Madrid: Editorial Complutense.

Santamaría, E. (1994). "Extranjero, nada menos que una palabra mayor", Revista de Sociología, N. 43, 63-70.

Santamaría, E. (2002). La incógnita del extraño. Una aproximación a la significación sociológica de la inmigración no comunitaria. Barcelona: Anthropos.

Sassen, S. (1999). La ciudad global. Nueva York, Londres, Tokio. Buenos Aires: Eudeba.

Schnapper, D. (1991). La France de l'intégration. Sociologie de la nation en 1990. París: Gallimard.

Tajfel, H. (1984). Grupos humanos y categorías sociales: estudios de psicología social. Barcelona: Herder.

Tarrius, A. (2007). La mundialización por lo bajo. Barcelona: Hacer Editorial.

Thomas, W. y Znaniecki, F. (2004): El campesino polaco en Europa y en América. Madrid: Centro de Investigaciones Sociológicas.

Tietze, N. (2003). Jeunes musulmans de France et d'Allemagne. Les constructions subjectives de l'identité. París: L'Harmattan:

Touraine, A. (1965). Sociologie de l'action. París: Seluil

Touraine, A. (1969). La Société post-industrielle:naissance d'une société. Seluil: París.

Touraine, A. (1973). La production de la société. París: Seluil.

Touraine, A. (1994). Qu'est-ce que la démocratie?. París: Fayard.

Touraine, A. (1997). Pourrons-nous vivre ensemble? Égaux et différents. París: Fayard. Turner, John C. (1990). Redescubrir el grupo social. Madrid: Morata.

Estudios de la Paz y el Conflicto, Revista Latinoamericana, IUDPAS-UNAH, Volumen 1, Número 1, enero-junio 2020, pp. 97-115. DOI: 10.5377/rlpc.v1i1.9518 
Wieviorka, M. (2012). "Du concept de sujet à celui de subjectivation/dé-subjectivation", FMSH Working Papers 16, 1-14. (Disponible online: https://halshs.archivesouvertes.fr/halshs-00717835/document).

Wieviorka, M. (2004). “El trato político de las identidades culturales”. En Touraine, A. et al.: Conocimiento e identidad. Barcelona: El Roure, 22-33.

Wieviorka, M. (2008). Neuf leçons de sociologie. París: Robert Laffont.

\section{REFERENCIA DEL AUTOR}

Antonio Álvarez-Benavides es Doctor en Sociología por la Universidad Complutense de Madrid y por la Ecole des Hautes Etudes en Sciences Sociales de París. Actualmente es profesor en la City University of New York e investigador en el Centre d'Analyse et d'Intervention Sociologiques (CADIS-Internacional) y en el Grupo de Estudios Socioculturales Contemporáneos (GRESCO-UCM). Ha sido profesor en la UC3M, la UVA, la UNED, y en la UNIR, y ha participado en más de veinte proyectos de investigación e intervención social en el ámbito público y privado, a nivel nacional e internacional. Cuenta con una veintena de publicaciones y colaboraciones en libros en España, Francia, Rumanía, Polonia y Argelia. Email: alvarezbenavides@gmail.com. ORCID: 0000-0002-4346-2219

Recibido: 01-11-2019

Aceptado: 14-11-2019

(c) (i) Licencia Creative Commons Reconocimiento 4.0 (CC BY 4.0).

Estudios de la Paz y el Conflicto, Revista Latinoamericana, IUDPAS-UNAH, Volumen 1, Número 1, enero-junio 2020, pp. 97-115. DOI: 10.5377/rlpc.v1i1.9518 